\title{
PATHOMORPHOLOGICAL FEATURES OF PRIMARY TUMOR AND P53 PROTEIN EXPRESSION AS PREDICTORS OF LOCAL RECURRENCE OF PROSTATE ADENOCARCINOMA UNDER HIFU TREATMENT CONDITIONS
}

\author{
Bakarev M.A. ${ }^{1}$, Levin V.P. ${ }^{2}$, Neimark A.I. ${ }^{2}$, Lushnikova E.L. ${ }^{1}$ \\ ${ }^{1}$ Institute of Molecular Pathology and Pathomorphology, Federal Research Center of Fundamental and Translational \\ Medicine, Novosibirsk, e-mail: pathol@inbox.ru; \\ ${ }^{2}$ Altai State Medical University, Ministry of Health of the Russian Federation, Barnaul, e-mail: \\ rector@agmu.ru
}

Aims. The study was aimed at examination of morphological features of the primary tumor and the p53 protein expression in localized prostate cancer in order to clarify the criteria for the prediction of local recurrence under the impact of high-intensity focused ultrasound combined with androgen deprivation.

Materials and methods.

Pathomorphological features of the primary tumor and the immunohistochemical expression of p53 tumor suppressor protein were analysed in preoperative biopsy samples and transurethral resection of prostate specimens from 31 patients with a localized form of prostate cancer (PC) with the presence or absence of local recurrence within 3 years after treatment with high-intensity focused ultrasound (HIFU).

Results.

It was demonstrated that the local recurrence of PC after HIFU therapy was associated with a predominance of less differentiated forms of adenocarcinoma (Gleason score 4+3, 8, and 9), the presence of cribrotic structures in the primary biopsy specimens, as well as with characteristics indicating a significant tumor volume such as the percentage of positive biopsy cores $\geq 40 \%$ and the percentage of tumor tissue in all specimens $\geq 10 \%$.

Immunohistochemical analysis of p53 expression in PC structures revealed its heterogeneous nature: a weak nuclear staining in a minority of tumor cell nuclei (less than 10\%) was observed in $23 \%$ of all cases; increased expression (weakly positive and strong reaction in more than $10 \%$ of nuclei) was reported in $40 \%$ of patients with recurrence $(\mathrm{OR}=22.6, \mathrm{p}<0.05)$.

Conclusions.

The significant association between p53 hyperexpression and PC local progression confirms the importance of immunohistochemical evaluation of this marker as a factor of unfavourable prognosis for patients with localized PC undergoing HIFU therapy.

Key words: prostate cancer, p53 expression, high-intensity focused ultrasound, pathomorphology

INTRODUCTION. Prostate cancer (PC) is one of the most prevalent forms of malignant neoplasms in men. It takes the first place by an annual increase in the morbidity rate, especially, in patients younger than 60 years old $(15.6 \%)$ [1]. Over the last few decades, the methods of diagnostics and treatment of PC have been improved, the share of its localized forms among newly diagnosed cases has increased to $44.8 \%$ in Russian Federation [1]. In addition to radical prostatectomy associated with a high risk of complications, alternative low invasive methods of treatment have been proposed. One of such methods is the ablation of the prostate by a high-intensity focused ultrasound (HIFU) $[2,3]$.

The key problem in the wide application of HIFU therapy in the primary treatment of PC is the necessity to develop the criteria for selection and more precise stratification of patients by the risk of progression, primarily, in the group of tumors with low or intermediate risk [4]. The most valuable information is provided by the morphological study: the degree of tumor differentiation (Gleason score) and indirect evaluation of tumor volume by the data obtained from a multifocal biopsy are considered to be the prognostic factors of categories I and II according to the recommendations of the College of American Pathologists [5].

Apart from a routine histological study, for the evaluation of the malignant potential of a 
neoplasm, molecular-biological markers are often used that reflect the aberrant activity of regulatory pathways associated with a high proliferative and metastatic potential $[4,5]$. For the inclusion of such markers in the list of the recommended ones, it is necessary to evaluate their prognostic significance in different types of treatment.

The mutation in the p53 tumor suppressor gene (TP53) that leads to the loss of its regulatory and proapoptotic functions is considered to be one of the most widespread molecular-genetic defects in tumors of different localization [6]. Some studies showed that TP53 gene mutation indicated an aggressive subtype of PC and could be considered an independent prognostic factor of cancerspecific survival after conservative management and radical prostatectomy [7, 8]. Mutant p53 protein is characterized by a prolonged half-life which leads to its accumulation in the nuclei of cells and makes it detectable by immunohistochemistry [6]. At the same time, the available published data on this marker in the conditions of ultrasound ablation of the prostate is sparse and controversial [9].

The aim of the study was to evaluate the pathomorphological features of the primary tumor and the expression of protein p53 in patients with localized PC in order to clarify the criteria of prognosis of local recurrence under the impact of highly intensive focused ultrasound in combination with androgen deprivation.

MATERIALS AND METHODS. The study population included 119 patients with PC.

The study protocol followed guidelines for experimental investigation with human subjects in accordance with the Declaration of Helsinki and was approved by the ethics committee. Written informed consent was obtained from each patient (or official representative) before the study.

Patients underwent HIFU therapy using the Ablatherm device (EDAP TMS S.A., France) with the preceding transurethral resection of the prostate (TURP) at the Urological Department of Regional Clinical Hospital of the Barnaul Railway Station. HIFU therapy was indicated to patients with verified localized PC (stage T2a-cN0M0) and somatic contraindications to radical prostatectomy or those who refused it. The follow-up period was 3 months to 3 years. The control multifocal biopsy was performed according to the planned schedule ( $12 \pm 3$ months) or when a biochemical recurrence was suspected. The indications for the TURP procedure during the followup were a decrease in PC volume before a repeated session of HIFU or the stricture of the prostatic urethra.

According to the results of morphological analysis of the control material, all patients were divided into two groups: Group I - 91 patients (mean age $65.8 \pm 8.5$ years) that did not have signs of tumor progression and Group II - 28 patients (mean age 67.6 \pm 7.9 years) that had local tumor recurrence (residual growth) of PC. In 21 cases (75\%), the recurrence was diagnosed relatively early (in 6-18 months after HIFU therapy).

In $27(30 \%)$ cases from Group I and in 11 (39\%) cases from Group II, ultrasound ablation of PC was performed in combination with hormonal therapy (HT). Flutamide (250 mg TID) was used for 1-3 months before HIFU therapy, along with goserelin (Zoladex) (3.6 mg every 28 days or 10.8 mg every 3 months for 3-6 months). 
The in-depth pathomorphological analysis was performed on 162 biopsy and TURP samples obtained from 31 patients (16 patients from Group I and 15 patients from Group II) randomly selected from the study population. The distribution of patients by age, clinical-laboratory parameters, and HT plans in the selected subgroups and corresponding groups of the study population was not significantly different.

Biopsy specimens and samples obtained at TURP were fixed in a $10 \%$ solution of neutral formalin, processed by the standard methods, and embedded in paraffin. The 5 - $\mu$ m-thick sections were stained with hematoxylin and eosin in combination with Perls' reaction, and by van Gieson method with additional staining of elastic fibers with Weigert's resorcin-fuchsin; the PAS reaction was used. Paraffin sections were analyzed using a universal research microscope Leica DM 4000B. Microphotopraphs were taken with a Leica DFC320 digital camera and Leica QWin V3 computer software.

An indirect evaluation of tumor volume in each case included assessing the percentage of positive biopsy cores, and the percentage of tumor structures in all available cores estimated morphometrically as the fraction of all tissue occupied by tumor (\%). The morphometrical analysis was performed using Leica QWin V3 computer software. The analysis of the association between the specified parameters and the disease recurrence included their dichotomization and selection of the threshold levels (cutoff values) that provided most significant association $(\geq 40 \%$ for the percentage of positive cores and $\geq 10 \%$ for the percentage of tumor tissue).

To assess the association between Gleason score and the probability of local recurrence after HIFU session, all the observations were divided into three Gleason score risk groups based on the updated data on 5-year cancer-specific survival rates for patients that underwent conventional treatment of PC [10]: 1) $\leq 3+4$ (20 cases); 2) 4+3 (7 cases); 3) 8-9 (4 cases). The cutoff value was set to $\leq 3+4 / \geq 4+3$.

To evaluate the malignant potential of the tumor, we performed the immunohistochemical study using monoclonal antibodies to p53 tumor suppressor protein (clone DO7, Monosan). The intensity of p53 expression was evaluated visually by a semiquantitative method $\left(0,1^{+}, 2^{+}, 3^{+}\right)$, and the fraction of labeled cells was estimated (only nuclear expression was scored). The final result was defined by the following criteria: negative reaction - lack of staining or expression of p53 less than in $10 \%$ of cells; weakly positive reaction $-1^{+}$-expression in $\geq 10 \%$ or $2^{+}$-expression in $10-50 \%$ of cells; strong reaction $-2^{+}$-expression in $>50 \%$ or $3^{+}$-expression in $\geq 10 \%$ of cells [8].

The evaluation of staining intensity is based on the data suggesting that a high degree of p53 expression significantly correlates with the gene mutation, while a weak reaction can be associated with a physiological accumulation of the protein in the conditions of cellular stress or disturbance of some regulatory interactions [11]. The $10 \%$ cutoff was often used for the evaluation of positive expression in the studies of PC $[8,12,13]$. A lower fraction of positive nuclei $(<10 \%)$ correlated stronger with the presence of a wild gene in the analysis of ovarian carcinoma [11]. 
Statistical analysis was performed using STATISTICA 12.0 software (StatSoft, Inc., USA). For relative values, the results were presented as a percentage, continuous variables were presented as median $(\mathrm{Me})$ and interquartile range $\left(25^{\text {th }}-75^{\text {th }}\right.$ percentile $)$. Mann-Whitney U-test was used for a quantitative comparison of two independent groups. Cross tabulation analysis was performed with the use of Pearson $\chi^{2}$ or Fisher's exact test; the odds ratio and $95 \%$ confidence interval $(95 \% \mathrm{CI})$ were calculated. Correlations were assessed using the Spearman's test. The differences between compared groups were considered significant at $\mathrm{p}<0.05$.

RESULTS. The majority of studies showed that the tumor volume in the material of multifocal biopsy of the prostate was of prognostic significance when evaluating the probability of biochemical recurrence, metastasis, and lethal outcome after different treatments of PC [4]. Calculating the percentage of positive biopsy cores is a simple and most often used method of its indirect evaluation. The median value of this parameter in patients with recurrence $(66.7 \%$; IR $41.6-$ $90.0 \%$ ) was significantly higher than in Group I (25.0\%; IR 16.7-35.4\%; p<0.001).

The analysis of distribution of cases revealed that in the majority of patients (81\%) from Group I, the fraction of positive cores in the pre-operative sample did not exceed $40 \%(\leq 4$ cores in 12-point biopsy), while in $80 \%$ of cases, the recurrence was associated with higher values of this parameter $(\mathrm{OR}=17.3 ; 95 \%$ CI 2.9-103.0; $\mathrm{p}=0.002)$ (Table 1$)$.

Table 1. The distribution of patients in Groups I and II by the parameters of the tumor volume and Gleason score in the samples taken before the session of HIFU therapy

\begin{tabular}{|c|c|c|c|c|c|}
\hline \multicolumn{2}{|l|}{ Parameters } & $\begin{array}{l}\text { Group I, } \\
\text { abs. }(\%)\end{array}$ & $\begin{array}{l}\text { Group II, } \\
\text { abs. }(\%)\end{array}$ & $\begin{array}{c}\text { OR } \\
(95 \% \mathrm{CI})\end{array}$ & $\mathrm{p}$ \\
\hline \multirow{2}{*}{$\begin{array}{l}\text { The percentage of } \\
\text { positive cores, \% }\end{array}$} & $<40$ & $13(81.3)$ & $3(20.0)$ & \multirow{2}{*}{$\begin{array}{c}17.3 \\
(2.9-103.0) \\
\end{array}$} & \multirow{2}{*}{0.002} \\
\hline & $\geq 40$ & $3(18.7)$ & $12(80.0)$ & & \\
\hline \multirow{2}{*}{$\begin{array}{l}\text { The percentage of tumor } \\
\text { structures, } \%\end{array}$} & $<10$ & $12(75.0)$ & $2(13.3)$ & \multirow{2}{*}{$\begin{array}{c}19.5 \\
(3.0-126.5)\end{array}$} & \multirow[b]{2}{*}{0.002} \\
\hline & $\begin{array}{c}10-29 \\
\geq 30\end{array}$ & $\begin{array}{l}3(18.8) \\
1(6.2)\end{array}$ & $\begin{array}{l}8(53.3) \\
5(33.3)\end{array}$ & & \\
\hline \multirow[b]{2}{*}{ Gleason score } & $\leq 3+4$ & $14(87.5)$ & $6(40.0)$ & \multirow{2}{*}{$\begin{array}{c}10.5 \\
(1.7-63.9)\end{array}$} & \multirow[b]{2}{*}{0.011} \\
\hline & $\begin{array}{l}4+3 \\
8-9\end{array}$ & $\begin{array}{c}2(12.5) \\
0(0)\end{array}$ & $\begin{array}{l}5(33.3) \\
4(26.7)\end{array}$ & & \\
\hline
\end{tabular}

Note: the dashed line indicates the cutoff threshold used at the feature dichotomization; OR - odds ratio; CI confidential interval.

The estimation of the overall percentage of tumor structures in all biopsy cores is a more complicated but more precise method from the morphometrical point of view. In patients with recurrence, median value of this parameter (20.4\%; IR 14.2-30.8\%) significantly exceeded the respective value in Group I (3.5\%; IR 2.3-12.2\%; $\mathrm{p}=0.001)$. At the same time, in $75 \%$ of observations without recurrence, the percentage of tumor tissue was lower than the cutoff threshold (10\%). Local progression in the majority of cases (87\%) was associated with higher values of this parameter $(\mathrm{OR}=19.5 ; 95 \% \mathrm{CI} 3.0-126.5 ; \mathrm{p}=0.002)$. In $1 / 3$ of cases in Group II, the tumor percentage exceeded 30\% (Table 1). 
A positive correlation was established between the indirect parameters of tumor volume (the percentage of positive biopsy cores and overall percentage of tumor structures in the primary biopsy samples) and local recurrence after HIFU therapy ( $r=0.63$ and 0.59 , respectively; $\mathrm{p}<0.001$ ).

Assessment of PC differentiation grade at the pre-operative stage revealed the prevalence of low risk cases with Gleason score $\leq 3+4$ ( $87.5 \%$ of cases); Gleason score $7(4+3)$ was registered only in $2(12.5 \%)$ cases. In Group II, there was a significant shift towards less differentiated forms: Gleason scores $7(4+3), 8$ and 9, in total, were diagnosed in $60 \%$ of cases, and their identification was significantly associated with the progression of $\mathrm{PC}$ after HIFU therapy $(\mathrm{OR}=10.5 ; 95 \% \mathrm{CI}$ 1.7-63.9; $\mathrm{p}=0.011$ ) (Table 1). A positive correlation was registered between the Gleason score risk group and the diagnostics of local recurrence $(\mathrm{r}=0.52, \mathrm{p}=0.003)$.

Tumor structures of the $4^{\text {th }}$ grade are a heterogeneous group of patterns. Some of them can have a special prognostic significance. Presently, there are data that confirm a significant correlation of the cribriform pattern with biochemical recurrence and distant metastases after radiotherapy and radical prostatectomy [14]. In the present study, cribriform complexes (Figure 1a), revealed in 21\% of preoperative samples from Group II as the leading component and in 5\% of cases as a secondary component, were not found in samples from Group I ( $\mathrm{p}=0.012)$.

In some cases, the primary biopsy samples in patients with recurrence contained other histological markers of an unfavorable prognosis, such as perineural invasion and intraductal carcinoma of the prostate ( 7 and 5\% of samples from Group II, respectively). The latter had a cribriform structure with foci of solidarization and preserved the contour of branching ducts in some places (Figure 1b).
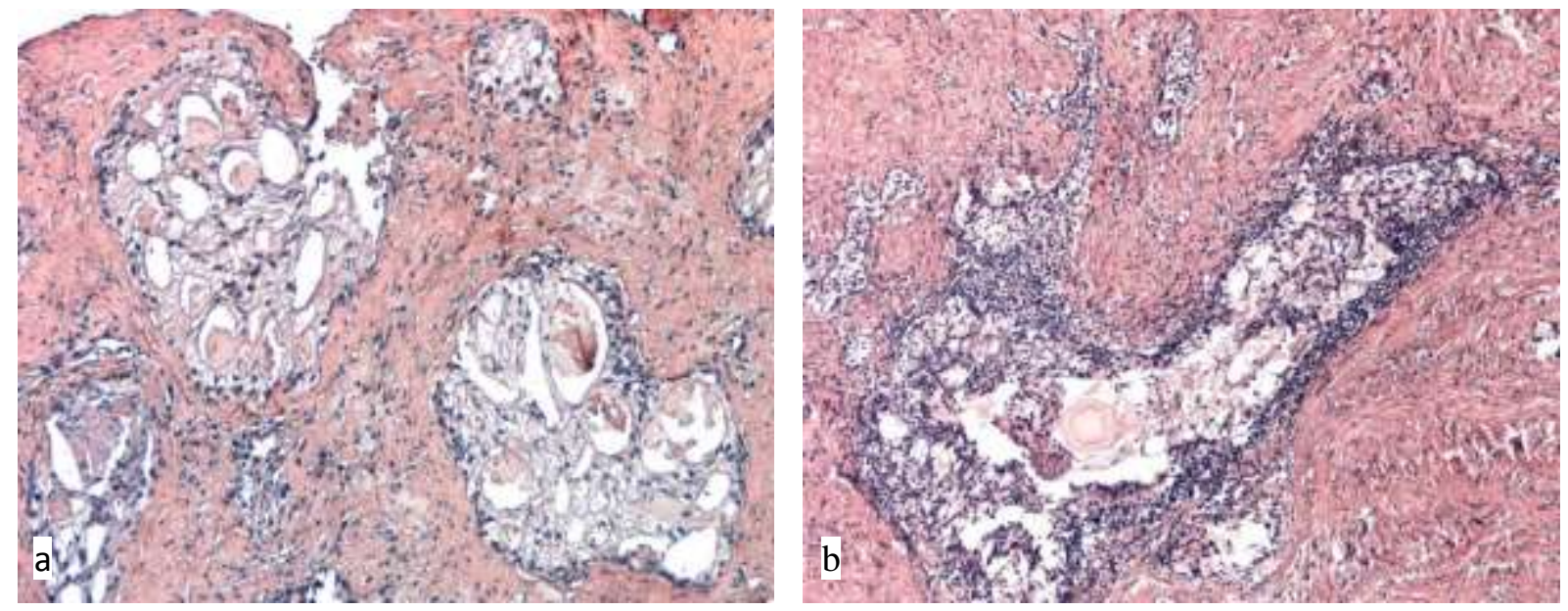

Figure 1. Cribriform structure in the biopsy sample (a) and TURP specimen (b) from Group II: acribriform clear cell adenocarcinoma; $b$-cribriform structures in the lumen of the branching duct (intraductal carcinoma of the prostate). Hematoxylin and eosin-stained. Magnification $\times 200$

The analysis of biopsy samples and TURP specimens obtained from patients with PC showed that the main background changes in prostate parenchyma were benign prostatic hyperplasia (BPH) (its signs were observed in $75 \%$ of available TURP samples) and focal atrophic or mixed atrophic and proliferative changes that prevailed in the peripheral zone of the prostate and, 
in many cases, were associated with the signs of chronic inflammation. The close association of simple atrophy and post-atrophic hyperplasia foci with moderate or prominent inflammatory cell infiltration (observed in $35 \%$ of cases) is often referred to as "proliferative inflammatory atrophy" (PIA). Topographical and molecular-genetic parallels with high grade prostatic intraepithelial neoplasia (HGPIN) and PC allow some authors to treat PIA as an early risk/precursor lesion to PC development [15].

The immunohistochemical evaluation of p53 expression revealed a nearly complete lack of specific staining in benign glands and nodes of BPH. In some cases, a weakly positive reaction was registered in single basal cells (Figure 2a). Focal accumulations of weakly positive nuclei of basal localization $\left(1^{+}\right.$-expression in 10-30\% of nuclei) were often seen in the areas of PIA (Figure $2 \mathrm{~b}$ ) and foci of HGPIN near the tumor. In the remote foci of HGPIN, the reaction was less expressed but still exceeded the baseline level (Figure 2c).
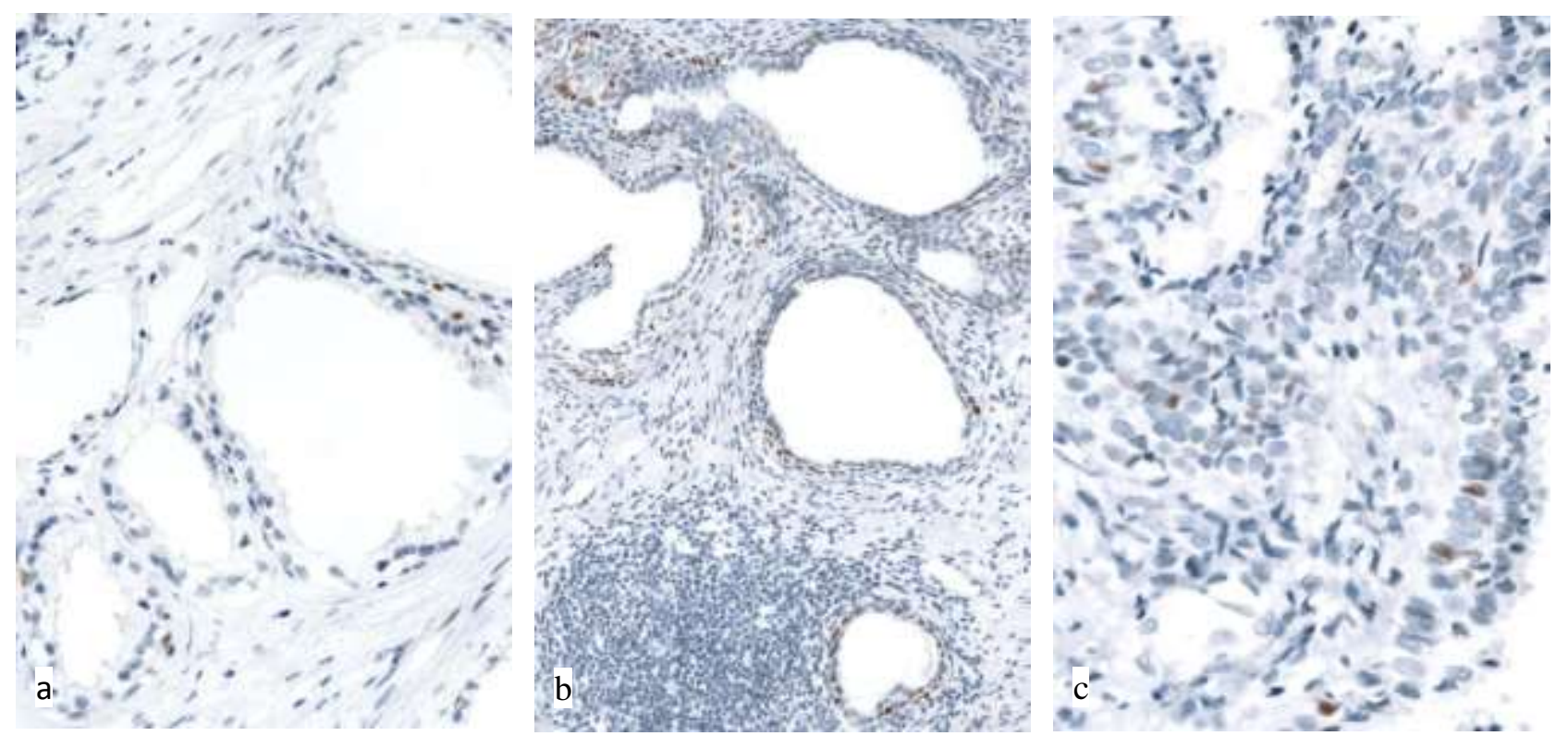

Figure 2. Expression of p53 in non-tumor parenchyma of the prostate in TURP samples from

Group I: $a$ - single p53-positive cells in the area of BPH. Magnification $x 400 ; b$-weakly positive reaction in basal cells in the area of PIA $\left(1^{+}, 28 \%\right.$ of cells). Magnification $\times 200 ; c-$ weak expression of 553 in the focus of PIN $\left(1^{+}, 6 \%\right.$ of cells). Magnification $\times 400$.

The expression of p53 in the structures of PC was heterogeneous. In 18 (58\%) cases, the expression lacked or was observed in single tumor cells nuclei (less than 1\%). In 7 cases (23\%), there was weak staining of some nuclei (up to $10 \%$ ), which was considered to be a negative reaction (Figure 3a). There were no significant differences in this parameter between the groups. 

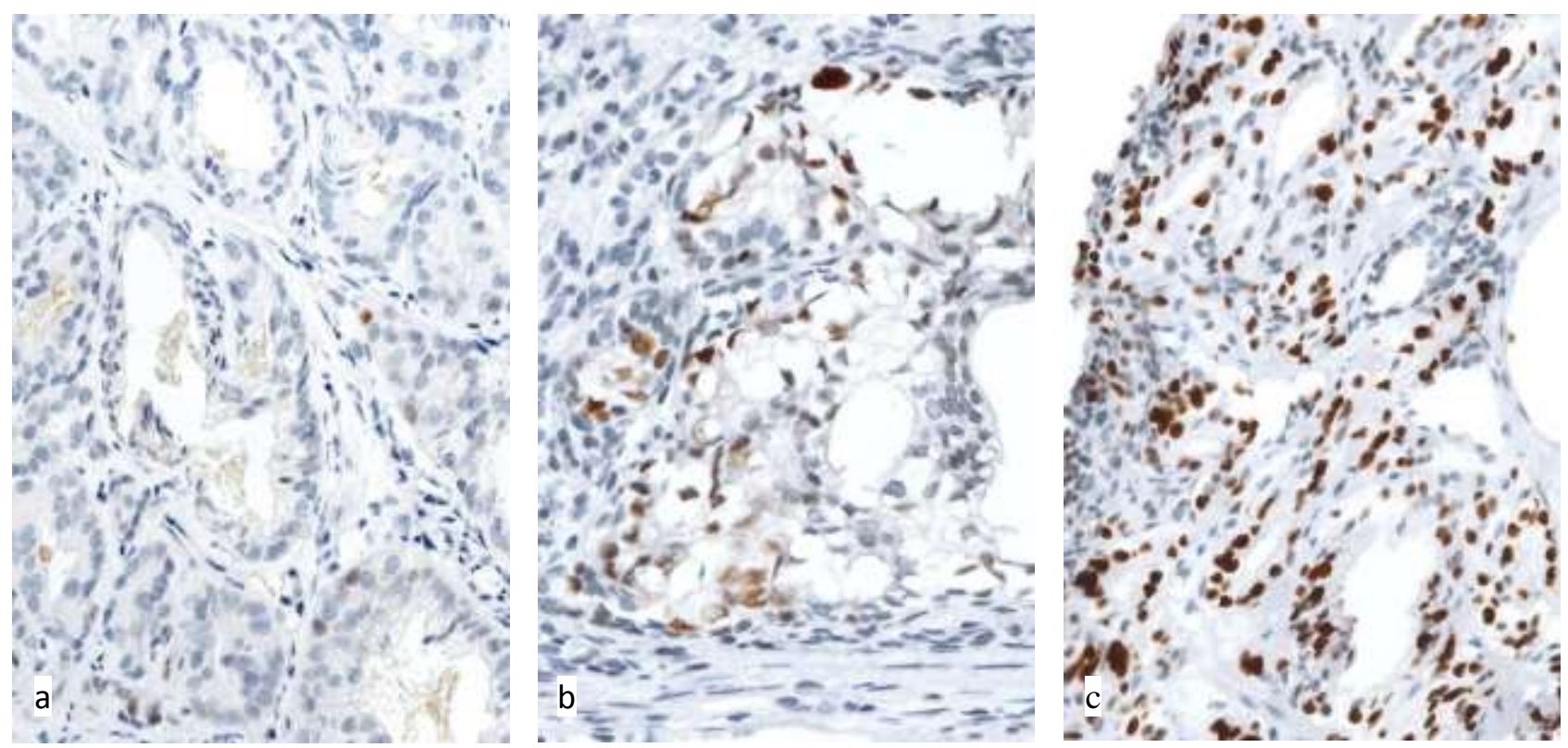

Figure 3. Expression of p53 in the structures of PC in biopsy samples from Groups I ( $a$ ) and II (b,

c): $a$ - single positive tumor cells in the focus of moderately differentiated adenocarcinoma; $b-$ weakly positive reaction in the focus of cribriform adenocarcinoma

$(2+, 31 \%$ of cells); $c$ - strong reaction in the focus of moderately differentiated adenocarcinoma $(3+, 73 \%$ of cells). Magnification $x 400$.

In 6 cases (19\%), PC structures in pre-operative samples displayed overexpression of p53: moderate or strong staining of 22-73\% nuclei of tumor cells (Figure 3b, 3c). All patients with the abnormal reaction in 10-21 months after the session of HIFU-therapy were diagnosed with recurrent PC (40\% of cases in Group II). A significant association between the hyperexpression of p53 and local progression $(\mathrm{OR}=22.6 ; 95 \%$ CI 1.1-446.8; $\mathrm{p}=0.040)$ was confirmed by the results of correlation analysis $(\mathrm{r}=0.53, \mathrm{p}<0.001)$.

In many primary biopsy samples with elevated expression of $\mathrm{p} 53$, there were other histological features indicative of a low degree of tumor differentiation and unfavorable outcome (Figure 3b). A statistically significant but weak correlation between p53 expression and the Gleason score risk group $(\mathrm{r}=0.40, \mathrm{p}=0.024)$ was established. Nevertheless, in some cases with recurrent PC, hyperexpression was observed in the cells of a moderately differentiated adenocarcinoma (Figure 3c). This might indicate that in certain cases, this marker could have an independent significance for prognosis and selecting the treatment options.

The p53 protein expression in the foci of precursor changes (PIA, PIN) suggests that the loss of p53 gene function may be an early event in PC carcinogenesis [15]. A weakly positive reaction does not necessarily indicate the presence of a mutation [11]. Still, in a number of studies using combination of laser microdissection, sequencing, and hybridization in situ the increased level of TP53 mutations and chromosome instability in HGPIN foci was shown [12].

CONCLUSIONS. Characteristics of the tumor, in particular, its volume and malignant potential, are significant factors that determine the probability of tumor cells survival after the exposure of prostatic tissue to high-intensity focused ultrasound. 
The study results suggest that the increased rate of local progression after HIFU treatment of localized PC is associated with the prevalence of less differentiated forms of adenocarcinoma (Gleason score 4+3, 8 and 9), the presence of cribriform structures in the primary biopsy samples, as well as with characteristics indicating a significant tumor volume such as the percentage of positive biopsy cores $\geq 40 \%$ (more than 4 cores from 12-point biopsy) and the percentage of tumor tissue in all specimens $\geq 10 \%$. The fact that even a small content of cribriform elements might be associated with further development of local recurrence suggests the feasibility of taking special account of cribriform subtype to select patients with increased risk of local progression after HIFU therapy.

The demonstrated association between the abnormal expression of p53 protein and local recurrence confirms the significance of immunohistochemical evaluation of this marker as a factor of unfavorable prognosis for PC patients undergoing HIFU therapy.

\section{FINANCIAL SUPPORT AND SPONSORSHIP \\ Nil.}

\section{CONFLICTS OF INTEREST}

The authors declare no conflict of interest

\section{SUPPLEMENTARY DATA (DOI)}

\section{REFERENCES}

1. Chissov V.I., Rusakov I.G. Prostate cancer morbidity in Russia [Zabolevaemost' rakom predstatel'noi zhelezy v Rossiiskoi federatsii]. Experimental and Clinical Urology - Eksperimental'naia $i$ klinicheskaia urologiia, 2011, vol. 3, no. 2, pp. 6-7.

2. Shossi K. World experience of prostate cancer HIFU-therapy [Mirovoi opyt HIFU-terapii RPZh]. Experimental and Clinical Urology - Eksperimental'naia i klinicheskaia urologiia, 2011, vol. 3, no. 2, pp. 44-47.

3. Limani K., Aoun F., Holz S. et al. Single high intensity focused ultrasound session as a whole gland primary treatment for clinically localized prostate cancer: 10-year outcomes. Prostate Cancer, 2014, vol. 2014, pp. 1-7, doi: 10.1155/2014/186782.

4. Hoogland A.M., Kweldam C.F., van Leenders G.J.L.H. Prognostic histopathological and molecular markers on prostate cancer needle-biopsies: a review. BioMed Research International, 2014, vol. 2014, pp. 1-12, doi 10.1155/2014/341324.

5. Ross J.S., Jennings T.A., Nazeer T. et al. Prognostic factors in prostate cancer. American Journal of Clinical Pathology, 2003, vol. 120, suppl. 1, pp 85-100, doi 10.1309/pw69k48rrfjlxkbd.

6. Rivlin N., Brosh R., Oren M. et al. Mutations in the p53 Tumor suppressor gene: Important milestones at the various steps of Tumorigenesis. Genes Cancer, 2011, vol. 2, no. 4. pp. 466-474, doi: $10.1177 / 1947601911408889$.

7. Kudahetti S., Fisher G., Ambroisine L. et al. p53 immunochemistry is an independent prognostic 
marker for outcome in conservatively treated prostate cancer. BJU International, 2009, vol. 104, pp. 20-24, DOI: 10.1111/j.1464-410X.2009.08407.x.

8. Kluth M., Harasimowicz S., Burkhardt L. et al. Clinical significance of different types of p53 gene alteration in surgically treated prostate cancer. International Journal of Cancer, 2014, vol. 135, no. 6, pp. 1369-1380, doi: 10.1002/ijc.28784.

9. Fomkin R.N., Voronina E.S., Popkov V.M. et al. Prognostic significance of molecular biological, morphological and clinical markers in evaluating the effectiveness of treatment of localized prostate cancer by high intensity focused ultrasound [Prognosticheskoe znachenie molekuliarnobiologicheskikh, morfologicheskikh i klinicheskikh markerov $\mathrm{v}$ otsenke effektivnosti lecheniia lokalizovannogo raka predstatel'noi zhelezy vysokointensivnym sfokusirovannym ul'trazvukom]. Experimental and clinical urology - Eksperimental'naia i klinicheskaia urologiia, 2013, no. 4, pp. 2933.

10.Epstein J.I, Zelefsky M.J., Sjoberg D.D. et al. A Contemporary Prostate Cancer Grading System: A Validated Alternative to the Gleason Score. European Urology, 2016, vol. 69, no 3, pp. 428-435, doi 10.1016/j.eururo.2015.06.046.

11.Yemelyanova A., Vang R., Kshirsagar M. et al. Immunohistochemical staining patterns of p53 can serve as a surrogate marker for TP53 mutations in ovarian carcinoma: an immunohistochemical and nucleotide sequencing analysis. Modern Pathology, 2011, vol. 24, no. 9, pp. 1248-1253, doi 10.1038/modpathol.2011.85.

12.Al-Maghrabi J., Vorobyova L., Chapman W. et al. p53 Alteration and chromosomal instability in prostatic high-grade intraepithelial neoplasia and concurrent carcinoma: analysis by immunohistochemistry, interphase in situ hybridization, and sequencing of laser-captured microdissected specimens. Modern Pathology, 2001, vol. 14, no. 12, pp. 1252-1262, 10.1038/modpathol.3880471.

13.Guedes L.B., Almutairi F., Haffner M.C. et al. Analytic, Preanalytic, and Clinical Validation of p53 IHC for Detection of TP53 Missense Mutation in Prostate Cancer. Clinical Cancer Research, 2017, vol. 23, no. 16, pp. 4693-4703, doi 10.1158/1078-0432.CCR-17- 0257.

14. Kweldam C.F., Wildhagen M.F., Steyerberg E.W. et al. Cribriform growth is highly predictive for postoperative metastasis and disease-specific death in Gleason score 7 prostate cancer. Modern Pathology, 2015, vol. 28, no. 3, pp. 457-464, doi 10.1038/modpathol.2014.116.

15. Wang W., Bergh A., Damber J.E. Increased p53 immunoreactivity in proliferative inflammatory atrophy of prostate is related to focal acute inflammation. APMIS, 2009, vol. 117, no. 3, pp. 185-195, doi: 10.1111/j.1600-0463.2008.00006.x. 